OPEN ACCESS

Edited by:

Xiying Li,

Shaanxi Normal University, China

Reviewed by:

Xinghua Wang,

Qingdao University, China

Jiansheng $L i$,

Northwest Normal University, China

*Correspondence:

Sha Shen

yilushen0104@163.com

Specialty section:

This article was submitted to

Educational Psychology,

a section of the journal

Frontiers in Psychology

Received: 08 November 2021 Accepted: 03 December 2021

Published: 10 January 2022

Citation:

Sha J, Tang T, Shu H, He K and Shen S (2022) Emotional Intelligence,

Emotional Regulation Strategies, and Subjective Well-Being Among University Teachers: A Moderated Mediation Analysis.

Front. Psychol. 12:811260. doi: 10.3389/fpsyg.2021.811260

\section{Emotional Intelligence, Emotional Regulation Strategies, and Subjective Well-Being Among University Teachers: A Moderated Mediation Analysis}

\author{
Jingrong Sha',2, Tianqi Tang', Hong Shu', Kejian $\mathrm{He}^{3}$ and Sha Shen ${ }^{1 *}$ \\ ${ }^{1}$ College of Educational Science and Technology, Northwest Minzu University, Lanzhou, China, ${ }^{2}$ Key Laboratory of China's \\ Ethnic Languages and Information Technology of Ministry of Education, Northwest Minzu University, Lanzhou, China, \\ ${ }^{3}$ Faculty of Law and Public Administration, College of Science and Technology, Guizhou University, Guiyang, China
}

This study aimed to explore the mediating role of emotional regulation strategies in the relationship between emotional intelligence (El) and subjective well-being (SWB) among Chinese university teachers, and evaluate whether effort-reward imbalance moderated the mediating effect of emotional regulation strategies. A total of 308 Chinese university teachers were recruited for this study. The results showed that emotional regulation strategies played a partial mediating role in the relationship between El and SWB. Moreover, an effort-reward imbalance moderated the relationship between emotional regulation strategies and SWB. For individuals with more balanced perceptions, El had a significant effect on SWB via cognitive reappraisal, while for individuals with more imbalanced perceptions, El did not have a significant effect on SWB via cognitive reappraisal. These findings provide a better understanding of the effects of El and emotional regulation strategies on SWB, which could provide interventions for promoting SWB among teachers.

Keywords: emotional intelligence, emotional regulation strategies, subjective well-being, university teachers, effort-reward imbalance

\section{INTRODUCTION}

Teachers at universities experience high levels of stress and job burnout owing to the challenging nature of their work (Teles et al., 2020), thus they have a significantly lower level of subjective wellbeing (SWB) than other professionals (Grenville-Cleave and Boniwell, 2012). SWB is regarded as "evaluation of life satisfaction and positive and negative affective reactions to one's life" (Busseri and Sadava, 2011; Chan, 2013), which is believed to play an important role in physical and mental health (Pressman and Cohen, 2005; Tsaousis et al., 2007). Many studies have shown that SWB is important for teachers. It is not only associated with their professional performance (Rahm and Heise, 2019) and mental health (Xin et al., 2021), but also influences students' cognitive outcomes (Pietarinen et al., 2014; Hung et al., 2016) and well-being (Xin et al., 2021).

Considering the importance of SWB, a great deal of research attention has been devoted to this field, with particular attention to identifying the factors and mechanisms that affect it (Koydemir and Schütz, 2012). Teachers can be regarded as emotional workers who need to be sensitive to their jobs (Yin, 2015), and there is no doubt that emotional intelligence (EI) is an 
important factor that influences SWB. EI is defined as the ability to evaluate and express emotions, regulate emotions, and use emotional content in thinking and action (Mayer and Salovey, 1993). Previous studies have shown that one of the most reliable correlates of EI is SWB (Sánchez-Álvarez et al., 2016) and EI has been confirmed to be a strong predictor of SWB (Vergara et al., 2015; Lin et al., 2016). For example, Sánchez-Álvarez et al. (2016) conducted a meta-analysis of 25 studies with 8,520 participants, and the results showed that EI was positively correlated with SWB. Huang et al. (2018) used a structural equation model to conduct an empirical test on the survey data of 412 university students from two universities in South China and found that people with higher EI reported higher levels of SWB. In addition, studies have found that the improvement of teachers' EI can enhance their SWB (Vesely et al., 2013).

Although previous studies have indicated that EI is closely related to SWB, the relationship between EI and teachers' SWB is inconsistent (Lee et al., 2019). For example, Hassan (2019) explored the relationships between EI and SWB among university teachers and found a positive correlation between EI and SWB. However, some studies have found that EI has little influence on SWB. For example, Zeidner and Olnick-Shemesh (2010) found that EI had limitations in predicting SWB.

A possible explanation is that the relationship between EI and teachers' SWB is mediated or moderated by other factors. For example, previous studies have indicated that the relationships between EI and SWB may be influenced by emotion regulation strategies. Emotional regulation strategies include cognitive reappraisal and suppression of expression (Gross and John, 1998). Cognitive reappraisal is a form of cognitive change that involves construing a potentially emotion-eliciting situation in a way that changes its emotional impact (Lazarus and Alfert, 1964). Expressive suppression is a form of response regulation modulation that involves the suppression of persistent emotional expression behavior (Gross and John, 1998). Previous studies have shown a significant relationship between EI and emotional regulation strategies. For example, Quintana-Orts et al. (2020) confirmed there is a positive association between EI and emotion regulation strategies. Specifically, people with higher EI are more likely to choose effective emotional regulation strategies (Śmieja-Nęcka et al., 2011). In addition, studies have shown a significant relationship between emotion regulation strategies and SWB. For instance, Katana et al. (2019) discussed the influences of emotion regulation strategies on SWB, and the results showed that cognitive reappraisal aimed at increasing positive emotions was positively associated with higher SWB; suppression of positive emotion expression was negatively correlated with SWB. Therefore, do emotion regulation strategies mediate the relationships between EI and SWB among university teachers?

In addition, the relationship between EI, emotion regulation strategies, and SWB may be moderated by an effort-reward imbalance. Effort-reward imbalance is a source of work-related stress (Siegrist, 2010). According to affective events theory (Weiss and Cropanzano, 1996), the emotional experience accumulated in the work environment, together with other factors (including personality), shapes employees' work attitudes. In addition, affective event theory (Weiss and Cropanzano, 1996) proposed that the emotional state at work is a key carrier of the influence of personality and organization on job satisfaction and performance. Previous studies indicated that individuals with more positive affects at work are more likely to have higher EI (Lopes et al., 2006; Kafetsios and Zampetakis, 2008) and are prone to use more positive emotion regulation (MéridaLópez and Extremera, 2017). Thus, effort-reward imbalance may be a potential moderator for the mediating effect of emotion regulation strategies between EI and SWB.

Based on previous studies and related literature, this study aimed to investigate the mediating role of emotional regulation strategies between EI and SWB and explored whether effortreward imbalance moderated the mediating effect of emotional regulation strategies between EI and SWB among Chinese university teachers. Our hypotheses were as follows: (1) EI and emotional regulation strategies had positive effects on SWB; (2) emotional regulation strategies played a mediating role in the relationship between EI and SWB; and (3) effortreward imbalance moderated the mediating effect of emotional regulation strategies between EI and SWB.

\section{MATERIALS AND METHODS}

\section{Participants}

We distributed 350 questionnaires to three universities in western China. The teachers ranged in age from 23 to 58 years, with a mean age of 38.4 ( $\mathrm{SD}=9.97)$. After excluding incomplete questionnaires, 308 participants' responses were used in this study. After completing the questionnaire, all participants received a gift as a reward. Please see Table 1.

\section{Emotion Regulation Questionnaire}

This study used an emotion regulation questionnaire (ERQ) based on the two-stage emotional regulation process model proposed by Gross (2003). A total of 10 items were divided into two dimensions: cognitive reappraisal (six items) and expression suppression (four items). Each item was answered on a sevenpoint scale ( $1=$ very inconsistent, $7=$ very consistent). In this study, the Cronbach's alpha coefficient of the cognitive reappraisal score was 0.85 , and the Cronbach's alpha coefficient of the expression suppression score was 0.68 .

TABLE 1 | Socio-demographic characteristics of the participants $(n=308)$.

\begin{tabular}{lccc}
\hline & & Groups & Frequency (\%) \\
\hline Gender & Female & 142 & $46.1 \%$ \\
\multirow{2}{*}{ Age } & Male & 166 & $53.9 \%$ \\
& $\leq 35$ & 170 & $55.2 \%$ \\
Family background & $36-50$ & 106 & $34.5 \%$ \\
& $\geq 50$ & 32 & $10.3 \%$ \\
Only-child & Rural & 55 & $17.9 \%$ \\
& Towns & 253 & $82.1 \%$ \\
& Yes & 132 & $42.9 \%$ \\
& No & 176 & $57.1 \%$
\end{tabular}




\section{Emotional Intelligence Scale}

Emotional intelligence was measured using the Emotional Intelligence Scale (EIS) developed by Law et al. (2004). It contains 16 items, each item is answered on a seven-point scale ( 1 = strongly disagree, 5 = strongly agree), and the total sum score based on the 16 items varies between 16 and 112. The higher the score that participants receive, the higher their EI. The Cronbach's alpha coefficient in this study was 0.94 .

\section{Effort-Reward Imbalance Questionnaire for Teachers}

This study adopted the EFR questionnaire developed by Ren et al. (2019), which consists of two components (effort and reward). Effort contains 14 items, and the reward contains 14 items. Each item was answered on a five-point scale $(1=$ strongly disagree, 5 = strongly agree). According to Siegrist et al. (2004), the effort-reward ratio was computed for every respondent according to the formula $\mathrm{e} /(\mathrm{r} \times \mathrm{c})$ where " $\mathrm{e}$ " is the sum score of the effort scale, " $r$ " is the sum score of the reward scale and " $c$ " defines a correction factor for different numbers of items in the nominator and denominator, and the correlation factor of this study's questionnaire is 1 (14/14). The higher the ratio score participants get, the greater the imbalanced participants have, and the lower the ratio score participants get, the more balance participants have. The Cronbach's alpha coefficient of effort and reward in this study was 0.94 and 0.92 , respectively.

\section{Subjective Well-Being Scale}

The study used the Chinese version of the SWB Scale (Duan, 1996), which consists of 18 items. Each item was answered on a five-point scale ( $1=$ strongly disagree, $5=$ strongly agree). The higher the total score, the more subjective the well-being of the participants. Cronbach's alpha coefficient in this study was 0.85 .

\section{Procedure}

Data were collected using online questionnaires. First, we contacted the dean of academic affairs of the university, stated the purpose of the study, and received approval. Teachers were then invited to complete the questionnaire independently on weekdays.

\section{Ethics}

This study was approved by the Northwest Ethics Committee. Before participating in this study, all participants provided written informed consent to participate in the study.

\section{Analytical Strategy}

SPSS software (version 25.0) was used for data analysis. We first established the relationships among EI, effort-reward imbalance, emotional regulation strategies (cognitive reappraisal and expressive suppression), and SWB. Then, we used the SPSS macro PROCESS program to evaluate the mediating effect of emotional regulation strategies on EI and SWB and the moderating effect of effort-reward imbalance.

\section{RESULTS}

\section{Correlation Analysis of Emotional Intelligence, Emotional Regulation Strategies, Effort-Reward Imbalance, and Subjective Well-Being}

Pair correlation tests were conducted for each variable first, and the correlation coefficients among EI, emotional regulation strategies, effort-reward imbalance, and SWB are shown in Table 2.

\section{The Relationships Between Emotional Intelligence, Emotional Regulation Strategies, and Subjective Well-Being}

To analyze the influence of EI on SWB and the role of emotional regulation strategies, the SPSS macro PROCESS program was used to evaluate the mediating effect. Two regression equations were used to evaluate the following: first, the direct effect of EI on SWB; second, the mediating effects of cognitive reappraisal and expressive suppression between EI and SWB. The regression analysis results are listed in Table 3 . The results showed that EI significantly predicted SWB $(\beta=0.39, t=7.59, p=0.000)$, cognitive reappraisal $(\beta=0.34, t=6.37, p=0.000)$, and expression suppression $(\beta=-0.26, t=-4.65, p=0.000)$. Also cognitive reappraisal significantly predicted $\operatorname{SWB}(\beta=0.25, t=4.63$, $p=0.000)$, but expression suppression did not significantly predict SWB $(\beta=-0.10, t=-1.93, p=0.05)$. As shown in Figure $\mathbf{1}$, there was a mediating effect of cognitive reappraisal on the effect of EI on SWB.

Bias correction non-parametric percentage Bootstrap was further used to test the mediating effect, and the results are shown in Table 4. The direct effect value of EI on SWB was 0.17,

TABLE 2 | Statistical results of correlation analysis of main variables $(n==308)$.

\begin{tabular}{lcccccc}
\hline Variable & $\boldsymbol{M}$ (SD) & $\mathbf{1}$ & $\mathbf{2}$ & $\mathbf{3}$ & $\mathbf{4}$ & $\mathbf{5}$ \\
\hline El & $62.88(14.41)$ & 1 & $0.34^{\star *}$ & $-0.26^{* *}$ & $-0.16^{* *}$ & $0.40^{* *}$ \\
Cognitive reappraisal & $34.01(6.27)$ & & 1 & 0.05 & 0.01 & $0.35^{* \star}$ \\
Expressive suppression & $16.15(5.79)$ & & & 1 & 0.10 & $-0.17^{\star *}$ \\
Effort-reward imbalance & $1.16(0.60)$ & & & & 1 & $-0.20^{* \star}$ \\
SWB & $78.47(9.01)$ & & & & & 1 \\
${ }^{* *} p<<0.01$. & & & & & &
\end{tabular}

TABLE 3 | Mediation effect model test $(n=308)$.

\begin{tabular}{|c|c|c|c|c|c|c|}
\hline \multirow[t]{3}{*}{ Variable } & \multicolumn{3}{|c|}{ Model 1} & \multicolumn{3}{|c|}{ Model 2} \\
\hline & \multicolumn{3}{|c|}{ SWB } & \multicolumn{3}{|c|}{ SWB } \\
\hline & Effect of value & SE & $t$ & Effect of value & SE & $t$ \\
\hline El & 0.39 & 0.03 & $7.59^{\star \star \star}$ & 0.29 & 0.04 & $5.06^{\star \star \star}$ \\
\hline $\begin{array}{l}\text { Cognitive } \\
\text { reappraisal }\end{array}$ & & & & 0.25 & 0.08 & 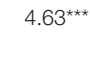 \\
\hline $\begin{array}{l}\text { Expression } \\
\text { suppression }\end{array}$ & & & & -0.10 & 0.08 & -1.93 \\
\hline$R^{2}$ & 0.15 & & & 0.22 & & \\
\hline$F$ & $57.72^{\star \star}$ & & & $28.26^{\star \star \star}$ & & \\
\hline
\end{tabular}


TABLE 4 | Bootstrap analysis of significance test of mediation effect $(n=308)$.

\begin{tabular}{|c|c|c|c|c|}
\hline The path & Effect of value & Effect of the amount & $\begin{array}{l}\text { Bootstrap } 95 \% \text { confidence } \\
\text { interval down line }\end{array}$ & $\begin{array}{l}\text { Bootstrap 95\% confidence } \\
\text { interval upper line }\end{array}$ \\
\hline Direct effect $(A \rightarrow C)$ & 0.17 & $85.71 \%$ & 0.10 & 0.24 \\
\hline Indirect effect $(A \rightarrow B \rightarrow C)$ & 0.07 & $14.29 \%$ & 0.02 & 0.13 \\
\hline Total effect & 0.24 & $100 \%$ & 0.18 & 0.31 \\
\hline
\end{tabular}

A, El; B, Cognitive Reappraisal; C, SWB.

accounting for $70.83 \%$ of the total effect, and the $95 \%$ interval was $(0.10,0.24)$, indicating that the direct effect was significant. The indirect effect value of cognitive reappraisal on EI and SWB was 0.07 , accounting for $29.17 \%$ of the total effect, with a $95 \%$ interval of $(0.02,0.13)$, indicating a significant mediating effect.

\section{The Moderated Mediation Analysis of Effort-Reward Imbalance}

Table 5 shows the results of the moderated mediation analysis of effort-reward imbalance. In Model 59 (Table 5), the interaction term between EI and effort-reward imbalance was not significantly associated with cognitive reappraisal $(\beta=-0.06$, $p=0.06)$ and $\operatorname{SWB}(\beta=0.07, p=0.16)$, indicating that effort-reward imbalance did not moderate the relationship between EI and cognitive reappraisal, as well as the relationship between EI and health SWB. Moreover, the interaction term between cognitive reappraisal and effort-reward imbalance was significantly related to SWB $(\beta=-0.35, p=0.01)$, which showed that the effort-reward imbalance moderated the relationship between cognitive reappraisal and SWB.

To further examine the moderation mediation effect, we conducted Model 14 (Table 5).

The interaction term between cognitive reappraisal and effort-reward imbalance was significantly associated with SWB ( $\beta=-0.28, p=0.04)$, as shown in Figure 2, the effort-reward imbalance moderated the effect of cognitive reappraisal on SWB. The index of moderated mediation was significant $(\beta=-0.04$,

TABLE 5 | Results of the moderated mediation analysis.

\begin{tabular}{|c|c|c|c|c|}
\hline \multirow{3}{*}{$\begin{array}{l}\text { Independent } \\
\text { variables }\end{array}$} & \multicolumn{2}{|c|}{ Model 59} & \multicolumn{2}{|c|}{ Model 14} \\
\hline & \multicolumn{2}{|c|}{ Subjective well-being } & \multicolumn{2}{|c|}{ Subjective well-being } \\
\hline & Coefficient & $t$ & Coefficient & $t$ \\
\hline $\begin{array}{l}\text { Emotional } \\
\text { intelligence }\end{array}$ & 0.17 & $5.18^{\star \star \star}$ & 0.17 & $5.16^{\star \star \star}$ \\
\hline Cognitive reappraisal & 0.33 & $4.25^{\star \star \star}$ & 0.32 & $4.19^{\star \star \star}$ \\
\hline $\begin{array}{l}\text { Effort-reward } \\
\text { imbalance }\end{array}$ & -2.33 & $-3.08^{\star \star}$ & -2.22 & $-2.95^{\star \star}$ \\
\hline $\begin{array}{l}\text { Emotional } \\
\text { intelligence } \times \text { effort- } \\
\text { reward } \\
\text { imbalance }\end{array}$ & 0.07 & 1.40 & & \\
\hline $\begin{array}{l}\text { Cognitive } \\
\text { reappraisal } \times \text { effort- } \\
\text { reward } \\
\text { imbalance }\end{array}$ & -0.34 & $-2.44^{\star}$ & -0.27 & $-2.08^{\star}$ \\
\hline$R^{2}$ & 0.24 & & 0.24 & \\
\hline$F$ & $19.80^{\star \star \star}$ & & $24.18^{\star \star \star}$ & \\
\hline
\end{tabular}

$95 \% \mathrm{CI}=-0.083,-0.005)$. For individuals with more balanced perceptions, EI had a significant effect on SWB via cognitive reappraisal $(\beta=0.07,95 \% \mathrm{CI}=0.039,0.117)$. As for individuals with more imbalanced perceptions, EI had no significant effect on SWB via cognitive reappraisal $(\beta=0.02,95 \% \mathrm{CI}=-0.013,0.065)$.

\section{DISCUSSION}

This study evaluated the relationships between EI, emotional regulation strategies, effort-reward imbalance, and SWB among Chinese university teachers. The results showed that EI and emotional regulation strategies were significant predictors of SWB. In addition, this study also revealed that EI affects SWB through emotional regulation strategies. Moreover, an effortreward imbalance moderated the relationship between emotional regulation strategies and SWB.

The results of this study show that EI positively predicted SWB, which was consistent with previous studies (e.g., SánchezÁlvarez et al., 2016; Szczygieł and Mikolajczak, 2017). According to EI theory, as individuals with high EI are good at understanding and managing their emotions, they are more likely to cope better with the stresses and troubles of daily life (Zeidner et al., 2012). In addition, people with high EI are more likely to have good interpersonal relationships and prosocial behavior (Wood et al., 2007). Therefore, people with high EI are prone to have a higher level of SWB (Zeidner et al., 2009).

In addition, the results of this study indicate that emotional regulation strategies play a mediating role in the relationship between EI and SWB. Specifically, this study indicated that only cognitive reappraisal mediated the relationship between EI and SWB among Chinese university teachers. Previous studies have suggested that cognitive reappraisal and expression suppression are different aspects and have different neural mechanisms (Gross and John, 2003). Cognitive reappraisal exhibits preferential regulatory advantage, which occurs at an early stage of emotion generation. Therefore, the expression of emotion can change before the emotional response is fully generated (Schutte et al., 2009). In addition, instead of avoiding affective states, cognitive reappraisal deals with emotions by living with negative emotions. Specifically, in an embarrassing situation, they do their best to alter the circumstances and change the emotional consequences of the situation (Schutte et al., 2009). Moreover, studies have shown that cognitive reassessment not only reduces negative emotions and behavioral expression, but also requires relatively few cognitive resources, which can be used effectively in the social environment (Gross, 1999; Richards and Gross, 2000; John and Gross, 2004; Gross et al., 2006). Therefore, cognitive reevaluation, 


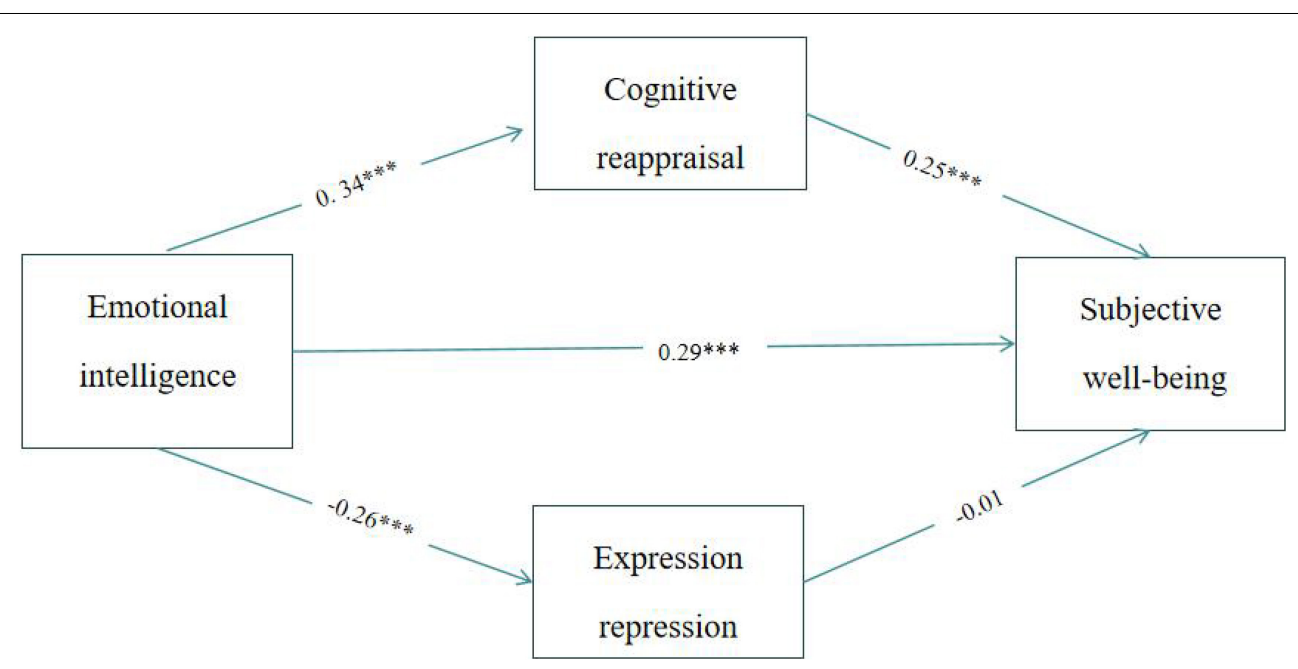

FIGURE 1 | The relationship models of El, emotional regulation strategies, and SWB. ${ }^{\star \star *} p<0.001$.

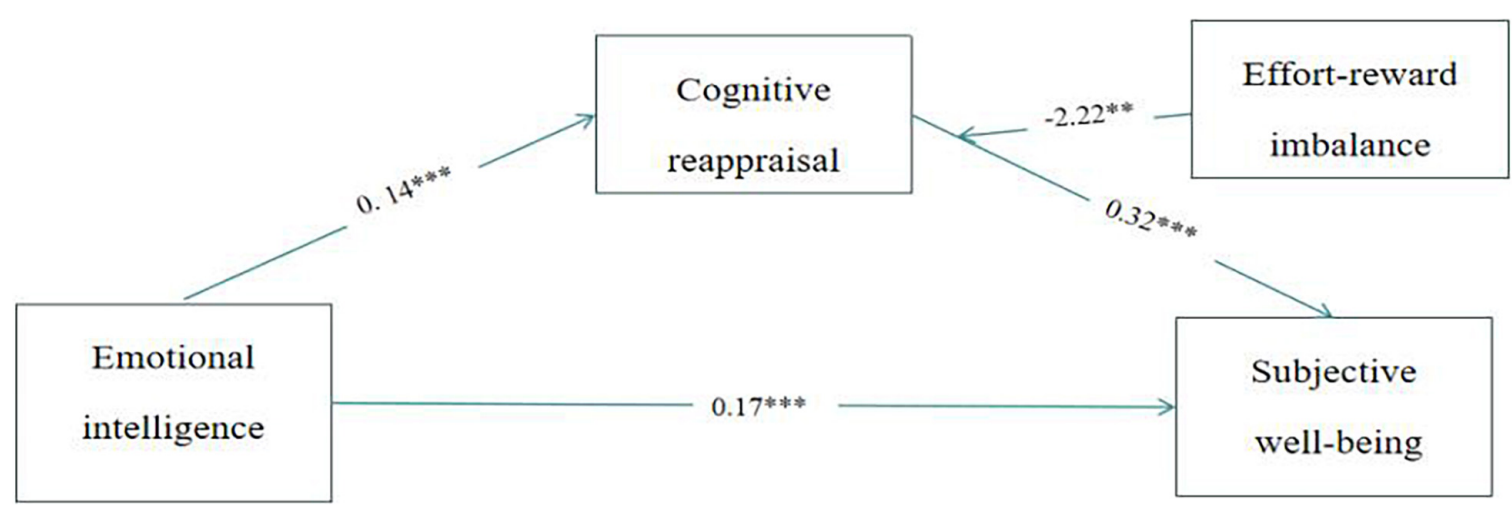

FIGURE 2 | The moderation mediate effect. ${ }^{* *} p<0.01 ;{ }^{* * *} p<0.001$.

as a healthy emotion regulation strategy, can better promote an individual's SWB (Haga et al., 2009).

More importantly, the study found that effort-reward imbalance moderated the relationship between emotional regulation strategies and SWB. For individuals with more balanced perceptions, EI had a significant effect on SWB via cognitive reappraisal, while for individuals with more imbalanced perceptions, EI had no significant effect on SWB via cognitive reappraisal. These results are in line with previous theories and studies. Affective events theory and affective event theory all proposed that the emotional experience accumulated in the work environment shapes employees' work attitudes. In addition, previous studies have shown that work affects are associated with EI and emotion regulation. More importantly, the results indicate that, compared with negative affect, the positive affect is stronger. This is an important finding that supports the growing evidence that positive affect takes precedence over negative affect as a predictor of work outcomes (Thoresen et al., 2003). As a source of human power (Isen, 2003) and positive affect promote the construction of personal and social resources (Fredrickson, 2001; Lyubomirsky et al., 2005). Therefore, the individuals with higher EI are more likely to adopt positive emotion regulation strategies which follow these "broadening and build" strategies, leading to higher a level of SWB.

This study had some limitations. First, the study used a cross-sectional design, which made it difficult to explore causal interpretations of these variables. A longitudinal study design is required in the future. Second, participants were recruited from the western cities of China, which may limit the generalization of the findings. Compared with the eastern coastal cities, the economy of northwest China is relatively backward, and previous studies have indicated that the economic level is closely related to SWB (Ngamaba et al., 2018; Ding et al., 2021) and EI (Shukla and Srivastava, 2016; Karapetyan, 2021). Future studies should expand the city of the participants.

These results provide a better understanding of the relationship between EI, emotional regulation strategies, and SWB, and expand the reports of potential causes of teachers' SWB from other studies. In addition, the present study has important theoretical significance for developing the theory of SWB, which expands the study of potential factors of university teachers' SWB and uncovers the mechanisms between EI and SWB. Although many studies have explored the relationships between EI and 
SWB and tried to explore the potential mechanism between them, only a few studies have investigated the role of emotional regulation strategies. Thus, whether emotional regulation strategies mediate the relationship between EI and SWB remains unclear. This study provides evidence of the mediating role of emotional regulation strategies. More importantly, the study provides evidence for developing interventions to improve teachers' SWB. For example, educational institutions and government departments can improve teachers' intelligence through a series of activities, such as group psychological counseling and mental health lectures. In addition, for teachers with low EI, cognitive therapy can be used to improve their emotional regulation strategies to enhance SWB.

\section{DATA AVAILABILITY STATEMENT}

The raw data supporting the conclusions of this article will be made available by the authors, without undue reservation.

\section{ETHICS STATEMENT}

This study was reviewed and approved by Ethics Committee of the College of Educational Science and Technology of Northwest Minzu University. Written informed consent was obtained from all participants for their participation in this study.

\section{REFERENCES}

Busseri, M. A., and Sadava, S. W. (2011). A review of the tripartite structure of subjective well-being: implications for conceptualization, operationalization, analysis, and synthesis. Pers. Soc. Psychol. Rev. 15, 290-314. doi: 10.1177/ 1088868310391271

Chan, D. W. (2013). Subjective well-being of Hong Kong Chinese teachers: the contribution of gratitude, forgiveness, and the orientations to happiness. Teach. Teach. Educ. 32, 22-30. doi: 10.1016/j.tate.2012.12.005

Ding, J., Salinas-Jiménez, J., and Salinas-Jiménez, M. d (2021). The impact of income inequality on subjective well-being: the case of China. J. Happiness Stud. 22, 845-866. doi: 10.1007/s10902-020-00254-4

Duan, J. (1996). The summary of subjective well-being. Adv. Psychol. Sci. 4, 46-51.

Fredrickson, B. L. (2001). The role of positive emotions in positive psychology: the broaden-and-build theory ofpositive emotions. Am. Psychol. 56, 218-226. doi: 10.1037/0003-066X.56.3.218

Grenville-Cleave, B., and Boniwell, I. (2012). Surviving or thriving? Do teachers have lower perceived control and well-being than other professions? Manag. Educ. 26, 3-5. doi: 10.1177/0892020611429252

Gross, J. J. (1999). "Emotion and emotion regulation," in Handbook of Personality: Theory and Research, 2nd Edn, eds L. A. Pervin and O. P. John (New York, NY: guilford Press), 525-552.

Gross, J. J., and John, O. P. (1998). Mapping the domain of expressivity: multimethod evidence for a hierarchical model. J. Pers. Soc. Psychol. 74, 170191. doi: 10.1037//0022-3514.74.1.170

Gross, J. J., and John, O. P. (2003). Individual differences in two emotion regulation processes: implications for affect, relationships, and well-being. J. Pers. Soc. Psychol. 85, 348-362. doi: 10.1037/0022-3514.85.2.348

Gross, J. J., Richards, J. M., and John, O. P. (2006). "Emotion regulation in everyday life," in Emotion Regulation in Families: Pathways to Dysfunction and Health, eds D. K. Snyder, J. A. Simpson, and J. N. Hughes (Washington, DC: American Psychological Association), 13-35.

\section{AUTHOR CONTRIBUTIONS}

JS proposed the initial idea. TT and HS conducted the research, collected, and analyzed the data. SS has made significant contributions by redesigning and modifying the framework of the present study. All authors participated in writing the manuscript and approved the submitted version.

\section{FUNDING}

This work was supported by the Key Laboratory of Ethnic Languages and Information Technology of Ministry of Education of China, Northwest Minzu University, Lanzhou, Gansu, China (KFKT202013, KFKT202016, KFKT202012, and 1001161310). The Young Doctor Foundation of Higher Education in Gansu Province "Research on the educational effect mechanism of the socialist core value 'unity of knowing and doing' of college students for nationalities in the new era" (No. 2021QB-071). The 14th Five-Year Planning Project of Education Science in Gansu Province "A study on the core behavior of patriotism of children in the new era" [No.: GS(2021)GHB1836]. Fundamental Research Funds for the Central Universities "Research on influencing factors of online education in post-epidemic era" (No. 31920210125).

Haga, S. M., Kraft, P., and Corby, E. K. (2009). Emotion regulation: antecedents and well-being outcomes of cognitive reappraisal and expressive suppression in cross-cultural samples. J. Happiness Stud. 10, 271-291. doi: 10.1007/s10902007-9080-3

Hassan, M. U. (2019). Emotional intelligence and subjective well being: exploration of teachers' burning dilemma. Behaviour 13, 101-112. doi: 10.33225/ppc/19. 13.101

Huang, J., Shi, H., and Liu, W. (2018). Emotional intelligence and Subjective well-being: altruistic behavior as a mediator. Soc. Behav. Pers. 46, 749-758. doi: $10.2224 /$ sbp.6762

Hung, C. H., Lin, C. W., and Yu, M. N. (2016). Reduction of the depression caused by work stress for teachers: subjective well-being as a mediator. Int. J. Res. Stud. Psychol. 5, 25-35. doi: 10.5861/ijrsp.2016.1461

Isen, A. M. (2003). "Positive affect as a source of human strength," in A Psychology of Human Strengths: Fundamental Questions and Future Directions for a Positive Psychology, eds L. G. Aspinwall and U. M. Staudinger (Washington, DC: American Psychological Association), 179-195. doi: 10.1037/105 66-013

John, O. P., and Gross, J. J. (2004). Healthy and unhealthy emotion regulation: personality processes, individual differences, and life span development. J. Pers. 72, 1301-1333. doi: 10.1111/j.1467-6494.2004.00298.x

Kafetsios, K., and Zampetakis, L. A. (2008). Emotional intelligence and job satisfaction: testing the mediatory role of positive and negative affect at work. Pers. Individ. Diff. 44, 712-722. doi: 10.1016/j.paid.2007.10.004

Karapetyan, L. V. (2021). Research on the relationship of students' emotional and personal well-being with intelligence indicators. Perspect. Sci. Educ. 49, 414-426. doi: 10.32744/PSE.2021.1.28

Katana, M., Röcke, C., Spain, S. M., and Allemand, M. (2019). Emotion regulation, Subjective well-being, and perceived stress in daily life of geriatric nurses. Front. Psychol. 10:1097. doi: 10.3389/fpsyg.2019.01097

Koydemir, S., and Schütz, A. (2012). Emotional intelligence predicts components of subjective well-being beyond personality: a two-country study using self- and 
informant reports. J. Posit. Psychol. 7, 107-118. doi: 10.1080/17439760.2011. 647050

Law, K. S., Wong, C. S., and Song, L. J. (2004). The construct and criterion validity of emotional intelligence and its potential utility for management studies. J. Appl. Psychol. 89, 483-496. doi: 10.1037/0021-9010.89.3.483

Lazarus, R. S., and Alfert, E. (1964). Short-circuiting of threat by experimentally altering cognitive appraisal. J. Abnorm. Psychol. 69, 195-205. doi: 10.1037/ h0044635

Lee, Y. H., R Richards, K. A., and Washhburn, N. S. (2019). Emotional intelligence, job satisfaction, emotional exhaustion, and subjective well-being in high school athletic directors. Psychol. Rep. 123, 2418-2440. doi: 10.1177/ 0033294119860254

Lin, D. T., Liebert, C. A., Tran, J., Lau, J. N., and Salles, A. (2016). Emotional intelligence as a predictor of resident well-being. J. Am. Coll. Surg. 223, 352-358. doi: 10.1016/j.jamcollsurg.2016.04.044

Lopes, P. N., Grewal, D., Kadis, J., Gall, M., and Salovey, P. (2006). Evidence that emotional intelligence is related to job performance and affect and attitudes at work. Psicothema 18(Suppl.), 132-138.

Lyubomirsky, S., King, L., and Diener, E. (2005). The benefits of frequent positive affect: does happiness lead to success? Psychol. Bull. 131, 803-855. doi: 10.1037/ 0033-2909.131.6.803

Mayer, J. D., and Salovey, P. (1993). The intelligence of emotional intelligence. Intelligence 17, 433-442. doi: 10.1016/0160-2896(93)90010-3

Mérida-López, S., and Extremera, N. (2017). Emotional intelligence and teacher burnout: a systematic review. Int. J. Educ. Res. 85, 121-130. doi: 10.1016/j.ijer. 2017.07.006

Ngamaba, K. H., Panagioti, M., and Armitage, C. J. (2018). Income inequality and subjective well-being: a systematic review and meta-analysis. Qual. Life Res. 27, 577-596. doi: 10.1007/s11136-017-1719-x

Pietarinen, J., Soini, T., and Pyhältö, K. (2014). Students' emotional and cognitive engagement as the determinants of well-being and achievement in school. Int. J. Educ. Res. 67, 40-51. doi: 10.1016/j.ijer.2014.05.001

Pressman, S. D., and Cohen, S. (2005). Does positive affect influence health? Psychol. Bull. 131, 925-971. doi: 10.1037/0033-2909.131.6.925

Quintana-Orts, C., Mérida-López, S., Rey, L., Neto, F., and Extremera, N. (2020). Untangling the emotional intelligence-suicidal ideation connection: the role of cognitive emotion regulation strategies in adolescents. J. Clin. Med. 9, 1-18. doi: $10.3390 /$ jcm 9103116

Rahm, T., and Heise, E. (2019). Teaching happiness to teachers - development and evaluation of a training in subjective well-being. Front. Psychol. 10:2703. doi: 10.3389/fpsyg.2019.02703

Ren, C., Li, X., Yao, X., Pi, Z., and Qi, S. (2019). Psychometric properties of the effort-reward imbalance questionnaire for teachers (teacher ERIQ). Front. Psychol. 10:2047. doi: 10.3389/fpsyg.2019.02047

Richards, J. M., and Gross, J. J. (2000). Emotion regulation and memory: the cognitive costs of keeping one's cool. J. Pers. Soc. Psychol. 79, 410-424. doi: 10.1037//0022-3514.79.3.410

Sánchez-Álvarez, N., Extremera, N., and Fernández-Berrocal, P. (2016). The relation between emotional intelligence and subjective well-being: a metaanalytic investigation. J. Posit. Psychol. 11, 276-285. doi: 10.1080/17439760. 2015.1058968

Schutte, N. S., Manes, R. R., and Malouff, J. M. (2009). Antecedent-focused emotion regulation, response modulation and well-being. Curr. Psychol. 28, 21-31. doi: 10.1007/s12144-009-9044-3

Shukla, A., and Srivastava, R. (2016). Meta analysis of the relationship between emotional intelligence and different behavioral intentions. Res. J. Bus. Manag. 10, 58-73. doi: 10.3923/rjbm.2016.58.73

Siegrist, J. (2010). Effort-reward imbalance at work and cardiovascular diseases. Int. J. Occup. Med. Environ. Health 23, 279-285. doi: 10.2478/v10001-010-0013-8

Siegrist, J., Starke, D., Chandola, T., Godin, I., Marmot, M., Niedhammer, I., et al. (2004). The measurement of effort-reward imbalance at work: european comparisons. Soc. Sci. Med. 58, 1483-1499. doi: 10.1016/S0277-9536(03)0 0351-4
Śmieja-Nęcka, M., Mrozowicz-Wrońska, M., and Kobylińska, D. (2011). Emotional intelligence and emotion regulation strategies. Stud. Psychol. 49, 55-64. doi: 10.2478/v10167-010-0040-x

Szczygieł, D., and Mikolajczak, M. (2017). Why are people high in emotional intelligence happier? They make the most of their positive emotions. Pers. Individ. Diff. 117, 177-181. doi: 10.1016/j.paid.2017.05.051

Teles, R., Valle, A., Rodríguez, S., Piñeiro, I., and Regueiro, B. (2020). Perceived stress and indicators of burnout in teachers at Portuguese higher education institutions (HEI). Int. J. Environ. Res. Public Health 17, 3248-3258. doi: 10. 3390/ijerph17093248

Thoresen, C. J., Kaplan, S. A., Barsky, A. P., Warren, C. R., and de Chermont, K. D. (2003). The affective underpinnings of job perceptions and attitudes: a metaanalytic review and integration. Psychol. Bull. 129, 914-945. doi: 10.1037/00332909.129.6.914

Tsaousis, I., Nikolaou, I., Serdaris, N., and Judge, T. A. (2007). Do the core self-evaluations moderate the relationship between subjective well-being and physical and psychological health? Pers. Individ. Diff. 42, 1441-1452. doi: 10. 1016/j.paid.2006.10.025

Vergara, A. I., Alonso-Alberca, N., San-juan, C., Aldás, J., and Vozmediano, L. (2015). Be water: direct and indirect relations between perceived emotional intelligence and subjective well-being. Austr. J. Psychol 67, 47-54. doi: 10.1111/ ajpy. 12065

Vesely, A. K., Saklofske, D. H., and Leschied, A. D. W. (2013). Teachers-the vital resource: the contribution of emotional intelligence to teacher efficacy and well-being. Can. J. Sch. Psychol. 28, 71-89. doi: 10.1177/0829573512468855

Weiss, H. M., and Cropanzano, R. (1996). Affective events theory. Res. Organ. Behav. 18, 1-74.

Wood, A. M., Joseph, S., and Linley, P. A. (2007). Coping style as a psychological resource of grateful people. J. Soc. Clin. Psychol. 26, 1076-1093. doi: 10.1521/ jscp.2007.26.9.1076

Xin, S., Liang, X., Sheng, L., and Zhao, Z. (2021). Changes of teachers' subjective well-being in mainland China (2002 2019): the perspective of cross-temporal meta-analysis. Acta Psychol. Sin. 53:875. doi: 10.3724/SP.J.1041.2021.00875

Yin, H. (2015). The effect of teachers' emotional labour on teaching satisfaction: moderation of emotional intelligence. Teach. Teach. 21, 789-810. doi: 10.1080/ 13540602.2014.995482

Zeidner, M., Matthews, G., and Roberts, R. D. (2009). What we Know About Emotional Intelligence: How It Affects Learning, Work, Relationships, and Our Mental Health. Cambridge, MA: MIT Press, doi: 10.7551/mitpress/7404.001. 0001

Zeidner, M., Matthews, G., and Roberts, R. D. (2012). The emotional intelligence, health, and well-being nexus: what have we learned and what have we missed? Appl. Psychol. Health Well Being 4, 1-30. doi: 10.1111/j.1758-0854.2011.01062.x

Zeidner, M., and Olnick-Shemesh, D. (2010). Emotional intelligence and subjective well-being revisited. Pers. Individ. Diff. 48, 431-435. doi: 10.1016/j.paid.2009. 11.011

Conflict of Interest: The authors declare that the research was conducted in the absence of any commercial or financial relationships that could be construed as a potential conflict of interest.

Publisher's Note: All claims expressed in this article are solely those of the authors and do not necessarily represent those of their affiliated organizations, or those of the publisher, the editors and the reviewers. Any product that may be evaluated in this article, or claim that may be made by its manufacturer, is not guaranteed or endorsed by the publisher.

Copyright (c) 2022 Sha, Tang, Shu, He and Shen. This is an open-access article distributed under the terms of the Creative Commons Attribution License (CC BY). The use, distribution or reproduction in other forums is permitted, provided the original author(s) and the copyright owner(s) are credited and that the original publication in this journal is cited, in accordance with accepted academic practice. No use, distribution or reproduction is permitted which does not comply with these terms. 